Published in final edited form as:

Biomacromolecules. 2020 March 09; 21(3): 1274-1284. doi:10.1021/acs.biomac.0c00041.

\title{
Simple Derivatization of RAFT-Synthesized Styrene-Maleic Anhydride Copolymers for Lipid Disk Formulations
}

\author{
Kevin M. Burridge, \\ Department of Chemistry and Biochemistry, Miami University of Oxford Ohio, Oxford, Ohio 45056, \\ United States \\ Benjamin D. Harding, \\ Department of Chemistry and Biochemistry, Miami University of Oxford Ohio, Oxford, Ohio 45056, \\ United States \\ Indra D. Sahu, \\ Department of Chemistry and Biochemistry, Miami University of Oxford Ohio, Oxford, Ohio 45056, \\ United States; Natural Science Division, Campbellsville University, Campbellsville KY 42718, \\ United States
}

\section{Madison M. Kearns,}

Department of Chemistry and Biochemistry, Miami University of Oxford Ohio, Oxford, Ohio 45056, United States

\section{Rebecca B. Stowe,}

Department of Chemistry and Biochemistry, Miami University of Oxford Ohio, Oxford, Ohio 45056, United States

\section{Madison T. Dolan,}

Department of Chemistry and Biochemistry, Miami University of Oxford Ohio, Oxford, Ohio 45056, United States

\section{Richard E. Edelmann,}

Center for Advanced Microscopy \& Imaging, Miami University, Oxford, Ohio 45056, United States

\section{Carole Dabney-Smith,}

Department of Chemistry and Biochemistry, Miami University of Oxford Ohio, Oxford, Ohio 45056, United States

\section{Richard C. Page,}

Department of Chemistry and Biochemistry, Miami University of Oxford Ohio, Oxford, Ohio 45056, United States

Corresponding Authors: Dominik Konkolewicz - Department of Chemistry and Biochemistry, Miami University of Oxford Ohio, Oxford, Ohio 45056, United States; d.konkolewicz@miamiOH.edu, Gary A. Lorigan - Department of Chemistry and Biochemistry, Miami University of Oxford Ohio, Oxford, Ohio 45056, United States; lorigag@ miamioh.edu.

Supporting Information

The Supporting Information is available free of charge at https://pubs.acs.org/doi/10.1021/acs.biomac.0c00041.

Peak assignments of the Fourier-transform infrared spectra and solution NMR spectra of the synthesized SMADs and representative

TEM images of SMADLPs made from POPC liposomes (PDF)

Complete contact information is available at: https://pubs.acs.org/10.1021/acs.biomac.0c00041

The authors declare no competing financial interest. 


\section{Dominik Konkolewicz,}

Department of Chemistry and Biochemistry, Miami University of Oxford Ohio, Oxford, Ohio 45056, United States

\section{Gary A. Lorigan}

Department of Chemistry and Biochemistry, Miami University of Oxford Ohio, Oxford, Ohio 45056, United States

\section{Abstract}

Styrene-maleic acid copolymers have received significant attention because of their ability to interact with lipid bilayers and form styrene-maleic acid copolymer lipid nanoparticles (SMALPs). However, these SMALPs are limited in their chemical diversity, with only phenyl and carboxylic acid functional groups, resulting in limitations because of sensitivity to low $\mathrm{pH}$ and high concentrations of divalent metals. To address this limitation, various nucleophiles were reacted with the anhydride unit of well-defined styrene-maleic anhydride copolymers in order to assess the potential for a new lipid disk nanoparticle-forming species. These styrene-maleic anhydride copolymer derivatives (SMADs) can form styrene-maleic acid derivative lipid nanoparticles (SMADLPs) when they interact with lipid molecules. Polymers were synthesized, purified, characterized by Fourier-transform infrared spectroscopy, gel permeation chromatography, and nuclear magnetic resonance and then used to make disk-like SMADLPs, whose sizes were measured by dynamic light scattering (DLS). The SMADs form lipid nanoparticles, observable by DLS and transmission electron microscopy, and were used to reconstitute a spin-labeled transmembrane protein, KCNE1. The polymer method reported here is facile and scalable and results in functional and robust polymers capable of forming lipid nanodisks that are stable against a wide $\mathrm{pH}$ range and $100 \mathrm{mM}$ magnesium.

\section{Graphical Abstract}

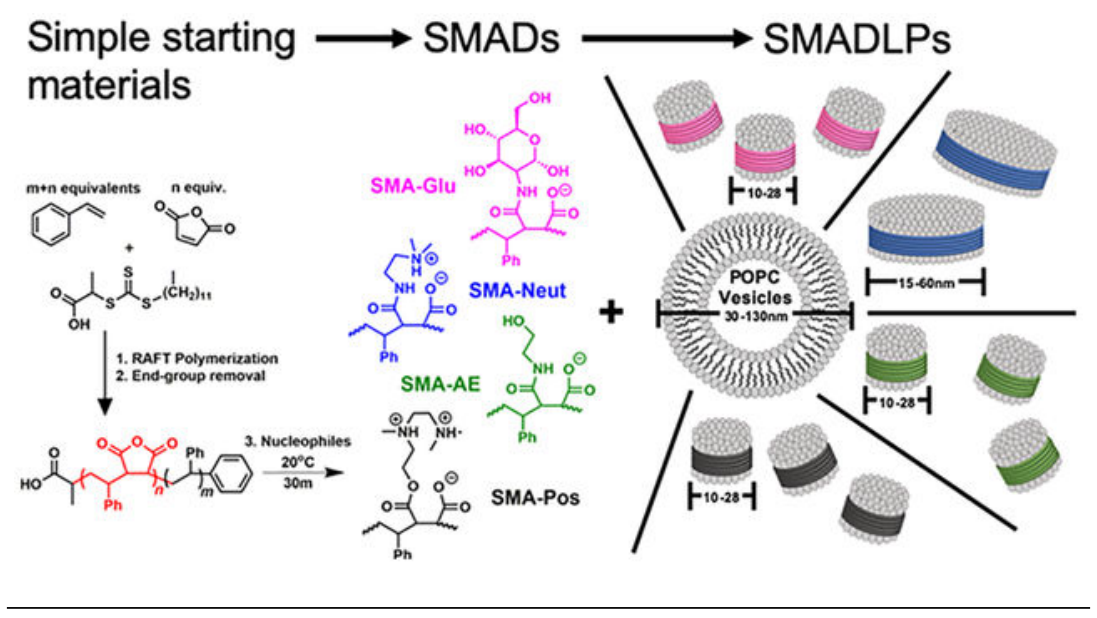

\section{INTRODUCTION}

Membrane proteins are ubiquitous and critical drug targets because of their roles in cell-cell signaling and recognition, immune response, ion transport, and other regulatory processes.

${ }^{1-3}$ However, they are challenging to characterize because of the innate heterogeneity of the 
lipid bilayer environment and surrounding water. To glean accurate structural information, membrane proteins must be incorporated into native-like membrane-mimetic environments, which enable retention of the protein's native conformation. ${ }^{4}$

Many types of membrane mimetics have been developed for isolation and characterization of membrane proteins. Membrane protein isolation typically requires disruption of the cell membrane and solubilizing its contents using micelle-forming detergents. ${ }^{5}$ However, micelles have high curvature and a different lateral pressure profile than the native bilayer, and thus, characterization data obtained from protein-detergent micelle samples carry the question of whether the data are biologically relevant.

In membrane protein characterization, a few classes of membrane mimetics have been developed, such as micelles, bicelles, liposomes, and nanodisks, each with their own applications. ${ }^{6}$ The name "bicelle" is a portmanteau combining the words "bilayer" and "micelle". To form a bicelle, bilayer-forming long-chain lipids are mixed with a short-chain detergent, such as CHAPSO or DHPC, to form a two-phased nanoparticle. The bilayer lipids form a bilayer which surrounds the protein of interest, and the detergents form a ring around the bilayer edge to shield the hydrophobic lipid tails from interaction with water. However, the select group of bicelle-forming detergents all fall on the hard-surfactant side of the spectrum and run the risk of denaturing the protein of interest. ${ }^{7,8}$

Liposomes are aggregates of lipid molecules in aqueous solution, which form a large spherical bilayer having an enclosed aqueous phase. This property can be useful in characterizing the activity of membrane transport proteins. Methods of preparing liposomes also quite often retain the native mimetic complex of protein and closely associated lipids. However, their large size confers anisotropy, making them unsuitable for solution nuclear magnetic resonance (NMR) applications. ${ }^{9}$ In addition, it is difficult to concentrate proteins into liposomes, which diminishes signal in biophysical experiments. ${ }^{10}$

Lipid disks, also called nanodisks, have recently attracted attention as novel membrane mimetic systems. In this architecture, bilayer-forming lipids are solubilized as nanoparticles by a belt of amphipathic macromolecules. The first generation of nanodisks utilized membrane scaffold protein or similar shorter peptides as the solubilizing unit. ${ }^{11-13}$ However, these peptides themselves can contribute background noise in certain membrane protein spectroscopic studies. Additionally, detergents must still be used to stabilize the protein of interest before addition of nanodisk-forming peptides. ${ }^{14}$ Amphipathic block copolymers are known to have interesting and useful phase behaviors, including the ability to form a variety of nanoparticles and architectures. ${ }^{15}$ Recently, such copolymers have been developed for nanodisk applications. When mixed with a lipid suspension, the hydrophobic portions of these polymers interact with the lipid acyl chains, inserting themselves into the bilayer. The hydrophilic portions make the lipid-protein-copolymer assembly soluble, disrupting the larger bilayer source, often without the assistance of detergents. ${ }^{16}$

The most common polymeric surfactant used to make nanodisks is the synthetic copolymer styrene-maleic acid (SMA). When a lipid sample, such as a liposome, interacts with SMA, SMA lipid nanoparticles (SMALPs) are formed. The transformation is usually complete at 
or above a 1:1 weight ratio of polymer/lipid. ${ }^{17}$ We have previously reported the synthesis of SMA suitable for use in SMALPs using reversible addition-fragmentation chain transfer (RAFT) radical polymerization (Scheme 1). ${ }^{18}$ RAFT polymerization of styrene and maleic anhydride affords SMA that generates SMALPs with tunable sizes between 10 and $50 \mathrm{~nm}$ based on the ratio of monomers used, on multigram scale, with a cost of dollars per gram of material.

There are, however, limits to the utility of SMA; the most common problems encountered are due to the diacids in the copolymer. Protonation of the acids or binding to divalent metal cations such as calcium or magnesium causes SMA to become too hydrophobic to maintain the lipid disk structure. The presence of magnesium at a concentration above $10 \mathrm{mM}$ or $\mathrm{pH}$ less than 6 often causes precipitation of the polymer, resulting in SMALP disassembly. ${ }^{19}$ This sensitivity to magnesium is unfortunate as many membrane proteins with enzymatic function, such as ATPases, require magnesium as a cofactor. Other groups have successfully overcome these problems by derivatizing cheaper commercially available materials (on their own, these materials are unable to form lipid disks), at times using somewhat expensive reagents, or long protocols with multiple reaction and precipitation steps for the derivatization. ${ }^{20-22}$

To overcome these limitations, nucleophilic ring opening of RAFT-synthesized styrenemaleic anhydride (SMAn) copolymers is explored in this article. This allows a wide range of chemical spaces to be explored. The rationale for the choice of nucleophile is summarized in Table 1. All the nucleophiles could be obtained for less than $\$ 2.00 / \mathrm{g}$.

All of the synthesized styrene-maleic anhydride copolymer derivatives (SMADs) are hypothesized to be milder surfactants than the parent SMA copolymer. Reacting SMA with glucosamine can mimic to some extent the alkyl glucosides which have proved useful in membrane protein work. ${ }^{24}$ SMA-Neut and SMA-Pos should be milder than SMA because of their zwitterionic character, mimicking surfactants such as CHAPSO and DHPC, which have been used in bicelle research. ${ }^{7}$ Finally, a different formulation of SMA-AE has been previously reported as useful in converting cheap yet impotent commercial SMA into a lipid-disk-forming material. ${ }^{23}$ SMA-AE has fewer charged groups than SMA and is therefore also expected to behave as a milder surfactant.

This work expands the biochemist's toolkit for studying membrane proteins by synthesizing styrene-maleic anhydride copolymers by RAFT and then took advantage of the high reactivity of the anhydride functional group to derivatize the polymers with various inexpensive, commercially available nucleophiles under ambient conditions in only $30 \mathrm{~min}$, with only one or two precipitation steps. The products, the new R-group added, and rationale for each choice are listed in Table 1. Conversion of the anhydride group was determined by infrared spectroscopy. The resulting polymers were then mixed with 1-palmitoyl-2-oleoylsn-glycero-3-phosphocholine (POPC) liposomes in order to assess their potential as new lipid disk polymers. 


\section{EXPERIMENTAL SECTION}

\section{Typical Synthesis of a One-Pot Block Copolymer of Poly(styrene-alt-maleic anhydride-b- styrene) (SMAn).}

All materials were obtained from commercial suppliers and used as received unless otherwise specified. The synthesis of poly(styrene-alt-maleic anhydride- $b$-styrene) was carried out as an adaptation of a previously described procedure. ${ }^{18}$ Briefly, styrene (3.6608 $\mathrm{g}, 35.1 \mathrm{mM})$, maleic anhydride $(0.98 \mathrm{~g}, 10 \mathrm{mM})$, and 2-

(dodecylthiocarbonothioylthio)propionic acid $(0.1404 \mathrm{~g}, 0.4 \mathrm{mM})$ were combined in a 20 $\mathrm{mL}$ vial and dissolved in $4.64 \mathrm{~g}$ of 1,4-dioxane. 1,1-Azobis(cyclohexanecarbonitrile) (0.0195 $\mathrm{g}, 0.008 \mathrm{mM}$ ) was added and dissolved. The contents of the vial were transferred to a $50 \mathrm{~mL}$ round-bottom flask with a magnetic stir bar, and a small aliquot of solution was set aside. The flask was capped with a rubber stopper and bubbled with nitrogen for $15 \mathrm{~min}$. The solution was heated to $90{ }^{\circ} \mathrm{C}$ for $20 \mathrm{~h}$. Once comparison by NMR with the previously set aside aliquot showed sufficient conversion $(\sim 80 \%)$, the polymer was purified by three sequential precipitations from tetrahydrofuran (THF) into a large excess of cold hexanes, yielding $4 \mathrm{~g}$ of yellow powder.

\section{End-Group Removal of Poly(styrene-alt-maleic anhydride-b-styrene).}

The polymer (ca. $4 \mathrm{~g}$ ) was dissolved in dioxane and combined with $2.4 \mathrm{~g}$ of benzoyl peroxide $(9.9 \mathrm{mM})$ in a $50 \mathrm{~mL}$ round-bottom flask. The flask was sealed with a rubber stopper and bubbled with nitrogen for $15 \mathrm{~min}$. The escape needle was left in the flask, and the flask was heated to $82{ }^{\circ} \mathrm{C}$ for $5 \mathrm{~h}$. Upon completion, the polymer was precipitated twice from THF into a large excess of cold hexanes, yielding a white to off-white powder. This material was stored in a desiccator at room temperature to prevent hydrolysis of the anhydride moiety by atmospheric moisture.

\section{Synthesis of 2-1 SMA-Glu.}

To a $20 \mathrm{~mL}$ glass vial was added $400 \mathrm{mg}$ of $2-1 \mathrm{SMAn}$, which had ca. $3 \mathrm{mmol} / \mathrm{g}$ of anhydride, for a total of $1.2 \mathrm{mmol}$ anhydride. The polymer was dissolved in minimal dimethylformamide (DMF). Then, to the vial were added simultaneously triethylamine (TEA) $(502.5 \mu \mathrm{L}, 3.6 \mathrm{mmol})$ and D-glucosamine ( $\mathrm{HCl}$ salt $)(0.3887 \mathrm{~g}, 1.8 \mathrm{mmol})$. The solution was stirred at room temperature for $30 \mathrm{~min}$. Longer stirring periods will result in an immobile cross-linked matrix. Then, the polymer was precipitated by adding this solution dropwise to rapidly stirring diethyl ether $(40 \mathrm{~mL})$ in an ice bath. The ether was decanted, and the polymer was washed with $20 \mathrm{~mL}$ of ice-cold ethyl acetate and mixed well. The ethyl acetate was decanted, and the polymer was dried in a vacuum oven at low temperature (ca. $50{ }^{\circ} \mathrm{C}$ ) for $30 \mathrm{~min}$ to remove all volatiles. Then, the sample was suspended in $0.1 \mathrm{M} \mathrm{HCl}$ (ca. $10 \mathrm{~mL}$ ), well mixed in a $15 \mathrm{~mL}$ centrifuge tube, and spun into a pellet at $7 \mathrm{k} \mathrm{rpm}$ for $5 \mathrm{~min}$. $\mathrm{HCl}$ was decanted, and the material was rinsed again with $10 \mathrm{~mL}$ of $\mathrm{HCl}$, spun down, and $\mathrm{HCl}$ was decanted. Finally, the polymer was freeze-dried, yielding $100 \mathrm{mg}$ of off-white powder. Conversion of the anhydride was confirmed by infrared spectroscopy. 


\section{Synthesis of 2-1 SMA-AE.}

To a $20 \mathrm{~mL}$ glass vial was added $400 \mathrm{mg}$ of $2-1 \mathrm{SMAn}$, which had ca. $3 \mathrm{mmol} / \mathrm{g}$ of anhydride, for a total of $1.2 \mathrm{mmol}$ anhydride. The polymer was dissolved in minimal DMF. Then, to the vial were added simultaneously TEA $(251.2 \mu \mathrm{L}, 1.8 \mathrm{mmol})$ and aminoethanol (109.0 $\mu \mathrm{L}, 1.8 \mathrm{mmol})$. The solution was stirred at room temperature for $30 \mathrm{~min}$. Then, the polymer was precipitated by adding this solution dropwise to rapidly stirring diethyl ether $(40 \mathrm{~mL})$ in an ice bath. The ether was decanted, and the polymer was washed with $20 \mathrm{~mL}$ of ice-cold ethyl acetate and mixed well. The ethyl acetate was decanted, and the polymer was dried in a vacuum oven at low temperature $\left(\mathrm{ca} .50^{\circ} \mathrm{C}\right.$ ) for $30 \mathrm{~min}$ to remove all volatiles. Then, the sample was suspended in $0.1 \mathrm{M} \mathrm{HCl}$ (ca. $10 \mathrm{~mL}$ ), well mixed in a $15 \mathrm{~mL}$ centrifuge tube, and spun into a pellet at $7 \mathrm{k} \mathrm{rpm}$ for $5 \mathrm{~min}$. $\mathrm{HCl}$ was decanted, and the material was rinsed again with $10 \mathrm{~mL}$ of $\mathrm{HCl}$, spun down, and $\mathrm{HCl}$ was decanted. Finally, the polymer was freeze-dried, yielding $190 \mathrm{mg}$ of off-white powder. Conversion of the anhydride was confirmed by infrared spectroscopy.

\section{Synthesis of 2-1 SMA-Pos.}

To a $20 \mathrm{~mL}$ glass vial was added $400 \mathrm{mg}$ of 2-1 SMAn, which had ca. $3 \mathrm{mmol} / \mathrm{g}$ of anhydride, for a total of $1.2 \mathrm{mmol}$ anhydride. The polymer was dissolved in minimal DMF. Then, to the vial was added 2-\{[2-(dimethylamino)ethyl]-methylamino $\}$ ethanol $(289.7 \mu \mathrm{L}$, $1.8 \mathrm{mmol})$. The solution was stirred at room temperature for $30 \mathrm{~min}$. Then, the polymer was precipitated by adding this solution dropwise to rapidly stirring diethyl ether $(40 \mathrm{~mL})$ in an ice bath. The ether was decanted, and the polymer was washed with $20 \mathrm{~mL}$ of ice-cold ethyl acetate and crushed with a metal spatula while being submerged. This was repeated twice for a total of $60 \mathrm{~mL}$ ethyl acetate used in washing. The ethyl acetate was decanted, and the polymer was dried in a vacuum oven at low temperature (ca. $50{ }^{\circ} \mathrm{C}$ ) for $30 \mathrm{~min}$ to remove all volatiles, followed by freeze-drying, yielding $245 \mathrm{mg}$ of off-white powder. Conversion of the anhydride was confirmed by infrared spectroscopy.

\section{Synthesis of 2-1 SMA-Neut.}

To a $20 \mathrm{~mL}$ glass vial was added $400 \mathrm{mg}$ of $2-1 \mathrm{SMAn}$, which had ca. $3 \mathrm{mmol} / \mathrm{g}$ of anhydride, for a total of $1.2 \mathrm{mmol}$ anhydride. The polymer was dissolved in minimal DMF. Then, to the vial was added $N, N$-dimethylethylenediamine $(196.9 \mu \mathrm{L}, 1.8 \mathrm{mmol})$. The solution was stirred at room temperature for $30 \mathrm{~min}$. Then, the polymer was precipitated by adding this solution dropwise to rapidly stirring diethyl ether $(40 \mathrm{~mL})$ in an ice bath. The ether was decanted, and the polymer was washed with $20 \mathrm{~mL}$ of ice-cold ethyl acetate and crushed with a metal spatula while submerged. This was repeated twice for a total of $60 \mathrm{~mL}$ ethyl acetate used in washing. The ethyl acetate was decanted, and the polymer was dried in a vacuum oven at low temperature (ca. $50{ }^{\circ} \mathrm{C}$ ) for $30 \mathrm{~min}$ to remove all volatiles, followed by freeze-drying, yielding $220 \mathrm{mg}$ of off-white powder. Conversion of the anhydride was confirmed by infrared spectroscopy.

\section{Synthesis of 2-1M/3-1M SMA.}

The anhydride moieties of the polymer were hydrolyzed to their succinic acid counterparts as previously described ${ }^{18}$ with slight modifications. Briefly, equal mass of polymer and THF 
$(1 \mathrm{~g})$ was combined in a vial and briefly heated to $95{ }^{\circ} \mathrm{C}$ while swirling to dissolve all the polymer. Then, a $4 \mathrm{X}$ molar excess of $\mathrm{NaOH}$ was added, and the mixture was heated at $50{ }^{\circ} \mathrm{C}$ for $24 \mathrm{~h}$. After this period, there are two layers, so another $10 \mathrm{~mL}$ of distilled water was added, and the mixture was heated for another $24 \mathrm{~h}$. At the end of this period, the solution was found to be stable at room temperature. THF and excess base were removed by dialysis in $3.5 \mathrm{kDa}$ cutoff tubing using two $1 \mathrm{~L}$ portions of ultrapure water. The polymer was collected in a $50 \mathrm{~mL}$ conical tube, frozen in a $-80{ }^{\circ} \mathrm{C}$ refrigerator overnight, and then lyophilized, yielding a white to off-white powder.

\section{Determination of Polymer Molecular Weight Parameters via Size Exclusion Chromatography.}

Approximately $5 \mathrm{mg}$ of polymer was weighed out and dissolved in either $1.5 \mathrm{~mL}$ of THF with $0.025 \%$ butylated hydroxy toluene or $1.5 \mathrm{~mL}$ of DMF with $0.01 \% \mathrm{LiBr}-\mathrm{THF}$ for the parent anhydride and DMF for the derivatives and SMA. To the resulting mixture was added two drops of toluene as the flow rate marker. The solution was filtered through a $0.22 \mu \mathrm{m}$ filter. Size exclusion chromatography was performed using an Agilent 1260 gel permeation chromatography system equipped with an autosampler, a guard and 2X PLgel MIXED B columns, and a refractive index detector. The eluent was THF or DMF running at $1 \mathrm{~mL} / \mathrm{min}$ at $25^{\circ} \mathrm{C}$. The system was calibrated with poly(methyl methacrylate) standards in the range of 617,000-1010, and the parent anhydride copolymer was corrected to polystyrene using the standard Mark-Houwink parameters $K_{\mathrm{MMA}}=12.8, a_{\mathrm{MMA}}=0.69, K_{\mathrm{Sty}}=11.4, a_{\mathrm{Sty}}=$ 0.716 . For the derivatives, no mass corrections could be done; no correctors exist for the derivatized anhydride units.

\section{Determination of $\mathrm{p} K_{\mathrm{a}}$.}

In most cases, approximately $15 \mathrm{mg}$ of polymer was weighed out and dissolved in $15 \mathrm{~mL}$ of distilled water with vigorous stirring. Dissolution was promoted by the addition of $50 \mu \mathrm{L}$ of $2 \mathrm{M} \mathrm{NaOH}$. The undissolved material was pelleted by centrifugation at 10,000 rpm for 10 min. The supernatant was transferred to a vial. A pH probe was submerged into solution, and $\mathrm{pH}$ was recorded with the addition of small volumes of $0.3-0.6 \mathrm{M} \mathrm{HCl}$. Because of the labile nature of esters in aqueous base, SMA-Pos was weighed out and dissolved in distilled water with vigorous stirring to promote dissolution of all visible materials. The SMA-Pos sample was then brought to low $\mathrm{pH}$ by the addition of a small volume of $6 \mathrm{M} \mathrm{HCl}$. Then, the $\mathrm{pH}$ was recorded with the addition of small volumes of $2 \mathrm{M} \mathrm{NaOH}$.

The $\mathrm{p} K_{\mathrm{a}}$ was determined by plotting the first derivative of the $\mathrm{pH}$. The first derivative can be easily obtained using eq 1 .

$$
\Delta \mathrm{pH}_{n}=\mathrm{pH}_{n}-\mathrm{pH}_{n-1}
$$

where $\Delta \mathrm{pH}_{n}$ is the change in $\mathrm{pH}$ at volume $n ; \mathrm{pH}_{n}$ is the $\mathrm{pH}$ at volume $n$; and $\mathrm{pH}_{n-1}$ is the $\mathrm{pH}$ at the volume preceding volume $n$. The $\mathrm{p} K_{\mathrm{a}}$ is equal to the $\mathrm{pH}$ at the volume corresponding to local minima in the derivative plot. Very low (under 2.5) and very high (over 11) values were not recorded as $\mathrm{p} K_{\mathrm{a}}$ values because of the high degree of dilution of 
these systems for which the ionization of water obscures observable changes in buffer capacity contributed by the polymers.

\section{Infrared Spectroscopy of SMA Derivatives.}

Infrared spectra were collected on a PerkinElmer Spectrum One FT-IR spectrometer. All samples were interrogated as dry solids. Spectra were normalized by setting the lowest transmittance value to zero and the highest transmittance near $4000 \mathrm{~cm}^{-1}$ to $100 \%$.

Preparation of POPC Vesicles.

A previously published procedure was used to prepare the POPC vesicles. ${ }^{18}$ POPC was chosen because the phosphatidylcholine head group is the most abundant head group in eukaryotic cell membranes. ${ }^{25,26}$ Powdered lipid was dissolved and suspended in a buffer containing $100 \mathrm{mM} \mathrm{NaCl}$ and $20 \mathrm{mM} N$-(2-hydroxyethyl)piperazine- $N^{\prime}$-ethanesulfonic acid (HEPES) at a pH 7.0 to a final concentration of $25 \mathrm{mM}$. The lipid slurry was vortexed vigorously to mix completely and vesicles were spontaneously formed, resulting in a homogeneous milky solution after 10 freeze/sonication cycles $\left(<30^{\circ} \mathrm{C}\right)$. Vesicle solutions were then frozen with liquid nitrogen and placed in a freezer overnight $\left(-20^{\circ} \mathrm{C}\right)$. Dynamic light scattering (DLS) was used to confirm the size of the vesicles the next day.

\section{Formation of Styrene-Maleic Acid Derivative Lipid Nanoparticles.}

SMADs were dissolved in buffer (20 mM HEPES, $100 \mathrm{mM} \mathrm{NaCl} \mathrm{pH} \mathrm{7)} \mathrm{at} \mathrm{an} \mathrm{approximate}$ concentration of $2.5 \%(\mathrm{~m} / \mathrm{v})$ and sonicated at $30-40{ }^{\circ} \mathrm{C}$ for several hours. The insoluble material was allowed to settle to the bottom for $24 \mathrm{~h}$. The styrene-maleic acid derivative lipid nanoparticles (SMADLPs) were formed by adding the top layer of the polymer solution dropwise to the POPC vesicles at a volume ratio of 1/1.5 lipid to polymer. Samples were then equilibrated via two freeze/sonication cycles. Samples were allowed to mix and equilibrate overnight at room temperature. The insoluble material was allowed to settle for $24 \mathrm{~h}$ before making the DLS measurement.

\section{DLS Measurement.}

DLS measurements were performed on a ZetaSizer Nano series (Malvern Instruments) at 25

${ }^{\circ} \mathrm{C}$ in disposable $40 \mu \mathrm{L}$ micro cuvettes. Data were collected for $20 \mathrm{~s}$ and averaged for $\mathbf{1 0}$ scans.

\section{Transmission Electron Microscopy.}

One drop of either liposome control or SMADLP sample was adsorbed to 200 mesh copper carbon-coated grids for $10 \mathrm{~s}$ for full absorbance. The grids were stained with two drops of $1.5 \%$ ammonium molybdate. Images were recorded using Joel-1200.

\section{pH Stability of SMADLPs.}

SMADLPs were formed by mixing together SMAD copolymers $(2.5 \% \mathrm{w} / \mathrm{v})$ and POPC vesicles $(2 \% \mathrm{w} / \mathrm{v})$ at a 7.5:1 weight ratio (6:1 by volume), followed by two freeze-sonication cycles, rotating at room temperature overnight, and then waiting at least $24 \mathrm{~h}$ for the insoluble material to settle to the bottom. Then, the turbidity of solutions of varying $\mathrm{pH}$ was 
measured in a 96-well plate. The supernatant SMADLP solution (10-20 $\mu \mathrm{L})$ was combined with $120 \mu \mathrm{L}$ of $0.1 \mathrm{M} \mathrm{NaCl}$ with $0.1 \mathrm{M}$ buffer-pH 3 HEPES, pH 5 acetate, pH 7 HEPES, and $\mathrm{pH} 9$ CHES. The optical density at $620 \mathrm{~nm}$ was used to measure turbidity, ${ }^{27}$ and all points were run in triplicates.

\section{$\mathrm{Mg}^{2+}$ Tolerance of SMADLPs.}

SMADLPs and SMALPs were prepared as described in the previous section. In a 96-well plate, $20 \mu \mathrm{L}$ of supernatant SMADLP solution was combined with $\mathrm{Mg}^{2+}$ containing buffer for a final volume of $150 \mu \mathrm{L}$ at the desired $\left[\mathrm{Mg}^{2+}\right]$ up to $100 \mathrm{mM}$. The optical density at 620 $\mathrm{nm}$ was used to measure turbidity, and all points were run in triplicates and baselined against a solution of SMADLPs at $0 \mathrm{mM} \mathrm{Mg}{ }^{2+}$.

\section{Preparation and Reconstitution of KCNE1 into Liposomes and Nanodisks for the CW-EPR Spectroscopic Study.}

The KCNE1 mutant T58C was overexpressed in BL21 Escherichia coli cells grown in TB minimal media with $50 \mu \mathrm{g} / \mathrm{mL}$ of chloramphenicol and $50 \mu \mathrm{g} / \mathrm{mL}$ of ampicillin. The cell cultures were incubated at $250 \mathrm{rpm}$ and $37 \mathrm{C}$ until an OD600 of 0.6 was reached; the cells were induced with $1 \mathrm{mM}$ isopropyl-1-thio-D-galactopyranoside. Purification of the KCNE1 protein was carried out using a previously described protocol. ${ }^{28}$ The pure protein was eluted in $0.5 \%$ dodecylphosphocho-line (DPC) detergent and concentrated using a Microcon YM-3 (molecular weight cutoff, 3000) filter (Amicon). The protein concentration was determined from A280 using a molecular extinction coefficient of $1.2 \mathrm{mg} / \mathrm{mL}$ protein per OD280 on a NanoDrop 2000c (Thermo Scientific). Protein purity was confirmed with sodium dodecyl sulfate polyacrylamide gel electrophoresis.

The protein sample was reduced with $2.5 \mathrm{mM}$ dithiothreitol, with gentle agitation at room temperature for $24 \mathrm{~h}$. The MTSL spin label was added in 10X molar excess to KCNE1 solution and incubated at room temperature $30 \mathrm{~min}$, followed by agitation at $37 .{ }^{\circ} \mathrm{C}$ for $3 \mathrm{~h}$ and then agitation at room temperature for the remaining $24 \mathrm{~h}$. The sample was then bufferexchanged into $50 \mathrm{mM}$ phosphate, $0.5 \%$ DPC, $\mathrm{pH}$ 7.0. After buffer exchange, samples were bound to nickel resin in a gravity column that was washed with $300 \mathrm{~mL}$ of $50 \mathrm{mM}$ phosphate, $0.05 \%$ DPC, pH 7.0 to remove excess spin label. Spin-labeled KCNE1 was eluted in $50 \mathrm{mM}$ phosphate, $250 \mathrm{mM}$ imidazole, $0.5 \%$ DPC, $\mathrm{pH} 7.0$.

Liposomes were prepared using the thin-film method. POPC and 1-palmitoyl-2-oleoyl-snglycero-3-phosphoglycerol (POPG) were measured in a 3:1 molar ratio with a final concentration of $100 \mathrm{mM}$. The powder lipid was dissolved in minimal chloroform, and then the chloroform was evaporated off with nitrogen. The flask was rotated during evaporation to form a thin film of lipids on the surface of the flask. The lipids were desiccated overnight, dissolved in $50 \mathrm{mM}$ phosphate $\mathrm{pH} \mathrm{7.0,} \mathrm{and} \mathrm{then} \mathrm{underwent} \mathrm{three} \mathrm{freeze-thaw} \mathrm{cycles} \mathrm{to} \mathrm{form}$ liposomes.

The concentrated spin-labeled KCNE1 protein was mixed with the liposomes to a 1:400 protein to lipid molar ratio. The sample underwent three freeze-thaw cycles to ensure incorporation of the protein into the liposome. The sample then underwent dialysis for $48 \mathrm{~h}$ in $4 \mathrm{~L}$ of dialysis buffer $(10 \mathrm{mM}$ imidazole and $0.1 \mathrm{mM}$ ethylenediaminetetraacetic acid at 
$\mathrm{pH}$ 7.0) with buffer changed twice daily. The completion of detergent removal was determined when the KCNE1-liposome sample became turbid and viscous when compared to predialysis.

KCNE1 inPOPC/POPG vesicles was reconstituted into nanodisks upon the addition of an SMAD similar to previous studies. ${ }^{29}$ Briefly, about $500 \mu \mathrm{L}$ of protein in the multilamellar vesicles was mixed with $2.5 \%$ SMAD solution (20 mM HEPES, $100 \mathrm{mM} \mathrm{NaCl}, \mathrm{pH} 7$ ) over $5 \mathrm{~min}$ and brought to a final weight ratio of 2:1 (polymer/lipid solution). The mixture was equilibrated at $4{ }^{\circ} \mathrm{C}$ for at least $3 \mathrm{~h}$ to allow for nanodisks to spontaneously form.

\section{RESULTS AND DISCUSSION}

\section{Gel Permeation Chromatography Analysis of SMA Derivatives.}

RAFT polymerization was used to synthesize the parent SMAn polymer. Gel permeation chromatography (GPC) analysis of the parent 2-1M SMAn shows that it is of the correct size and well-controlled with a dispersity less than 2.0 (Table 2 and Figure 1a). Small differences between the theoretical and experimental molecular weights are likely due to the use of poly(methyl methacrylate) standards to calibrate the size exclusion chromatography system. As for the derivatives, the calculated molecular weights are for the most part only slightly higher than expected (Table 2). SMA-Neut is very close or even slightly lower than the expected molecular weight. The mass of the other derivatives may be inflated by the aggregation behavior and differing Mark-Houwink parameters.

SMA-Glu was observed to have a very high dispersity, with multiple observable peaks (Figure 1b). The lowest molecular weight peak appears at the expected size (ca. $11 \mathrm{kDa}$ ); however, several larger peaks appear. This indicates that there is a large degree of branching and/or aggregation behavior. Indeed, if the SMA-Glu reaction is left stirring for longer than $30 \mathrm{~min}$, it will completely solidify. This may be due to a combination of nucleophilic substitution of the hydroxyl groups of glucosamine with anhydride and esterification of those same groups with carboxyl groups, catalyzed by TEA. More control could potentially be achieved by refluxing in aqueous base to selectively cleave the ester bonds that appear to be cross-linking the system (Figure 1).

GPC analysis of hydrolyzed SMA (Figure 1b) was also performed, but the comparison is complicated because dissolution of SMA in DMF requires neutralizing the acidic groups with $\mathrm{HCl}$, resulting in a mostly noncharged polymer. In any case, the low dispersity values for SMA-Neut, SMA-AE, and SMA-Pos indicate complete functionalization, which is supported by the IR data.

\section{$\mathrm{p} K_{\mathrm{a}}$ Analysis of SMA Derivatives.}

Many of the polymers displayed $\mathrm{p} K_{\mathrm{a}}$ values outside of the expected ranges for their functional groups. This is likely due to the differences between the local environments of these functional groups in a polymeric versus small-molecule form. There may be field effects for both amines and carboxylic acids, which favor the less ionic state (carboxylic acid or amine) and cause a shift in the $\mathrm{p} K_{\mathrm{a}}$ of the polymer compared to the small-molecule analogues. A protonated amine in proximity to a neutral amine or carboxylic acid will 
prevent more hydronium cations from approaching, decreasing the $\mathrm{p} K_{\mathrm{a}}$. Nearby hydrogen bond acceptors could help stabilize the protonated states of carboxylic acids and amines, increasing $p \mathrm{~K}_{\mathrm{a}}$. Moreover, a large concentration of negative charge such as with carboxylic acids strung together could cause an increase in $\mathrm{p} K_{\mathrm{a}}$ by attracting more hydronium and by the stabilization of the protonated state resulting from a decrease in local charge density; this phenomenon is known as the polyelectrolyte effect. ${ }^{30}$ As the protonation state changes, the magnitude of the polyelectrolyte effect also changes. This leads to a gradual change in apparent $\mathrm{p} K_{\mathrm{a}}$ over the course of the titration and generally smoothens the otherwise sharp $\mathrm{pH}$ transitions that occur outside the buffer region (Table 3).

The protonatable functional groups are also expected to be forced to the outside of a coiling polymer in which the styrene units are forced inside because of the hydrophobic effect. This agrees with the computed structure of dissolved SMA. ${ }^{16}$ This forced proximity may be what allows the carboxylic acids in some cases to have far higher $\mathrm{p} K_{\mathrm{a}}$ values than expected. From a thermodynamic standpoint, this would decrease the entropic penalty of intramolecular ring formation via hydrogen bonding; the coiled chain forces the functional groups into a favorable geometry for hydrogen bonding.

The hydrolyzed SMA parent material itself displays some interesting features. Although it does display one $\mathrm{p} K_{\mathrm{a}}$ in the expected range of 4.5 , there is also a reproducible shoulder in the $\Delta \mathrm{pH}$ curve at $\mathrm{pH} 9.6$, which is suspected to be a weak $\mathrm{p} K_{\mathrm{a} 2}$ where the first carboxyl group of each pair is protonated. This is consistent with the literature reporting $\mathrm{p} K_{\mathrm{a}}$ values of 6 and $10 .{ }^{19}$

SMA-Neut displayed $\mathrm{p} K_{\mathrm{a}}$ values in the expected range, corresponding to an amine(10.4) and a carboxylic acid (6.4). While the latter is on the high side for a carboxylic acid, it is consistent with prior work that has shown that the standard SMA copolymer exhibits a high $\mathrm{p} K_{\mathrm{a}}$ for its carboxylic acids. ${ }^{19}$ This is likely due to the proximity of carboxylic acids on the polymer chain and stabilization of a protonated carboxylic acid by the nearby amide carbonyl oxygen.

SMA-Pos showed only two $\mathrm{p} K_{\mathrm{a}}$ values, both close to those of SMA-Neut. These two polymers have analogous structures, but the $\mathrm{p} K_{\mathrm{a}}$ of 9.7 may be due to the amine nitrogen atoms sharing a proton, decreasing their $\mathrm{p} K_{\mathrm{a}}$ value relative to the typical amine $\mathrm{p} K_{\mathrm{a}}$ (ca. 10.5). A higher $\mathrm{p} K_{\mathrm{a}}$ may exist but may be too high for this simple method to detect.

SMA-Glu exhibits a single, wide, and very high $\mathrm{p} K_{\mathrm{a}}$ of 7.4 for its carboxylic acids. We propose that this is due to the numerous hydrogen bonding hydroxyl groups on the pendant glucose units, which cooperatively stabilize the protonated carboxylic acid. No pH-induced precipitation was observed for this polymer, which suggests that the glucose units shelter the protonated acid from the hydrophobic effect enough to prevent aggregation and precipitation. In addition, it is possible that any macromolecules which were capable of precipitating were dissolved and lost in one of the purification steps, which involved suspension in $0.1 \mathrm{M} \mathrm{HCl}$ and centrifugation into a pellet. It is noteworthy that two carbonyl stretches were observed for this polymer in the IR, leading us to conclude that some ester bonds may also have formed alongside the expected amide bonds, leaving some amines 
unreacted (Figure 3a). This is further supported by the GPC trace, which shows a peak with two shoulders that seem to indicate the presence of two-chain and three-chain species that could only form from slower esterification reactions. However, the difference in peak intensity by IR is too high to make these free amines significant contributors to $\mathrm{p} K_{\mathrm{a}}$.

Finally, SMA-AE seems to form a buffer region everywhere but the region expected for carboxylic acid, all the way from 10.5 to 8.5 . This observation was reproduced even when the polymer was fully dissolved in distilled water (ca. $25 \mathrm{mg} / \mathrm{L}$ solubility). The presence of the amide and the hydroxyl of the new functional group must provide an extremely favorable geometry for a stabilizing hydrogen bond network. No buffer region could be observed below 2.5 , but the polymer does precipitate below around 2.3 , suggesting a change in protonation state, but unfortunately not one we can easily measure because of the contribution of bulk water. To our knowledge, this is the first reported $\mathrm{p} K_{\mathrm{a}}$ for an SMA of this type.

\section{Infrared Spectroscopy of SMA Derivatives.}

In all cases, it appears that complete conversion of the anhydride to the nucleophilefunctionalized derivative has occurred (Figure 3). While it is possible that the weak peaks at 1778 and $1779 \mathrm{~cm}^{-1}$ (SMA-Glu and SMA-AE) correspond to unreacted anhydride, it is more likely that they correspond to contributions from intra- or intermolecular ester bond formation with the less reactive hydroxyl groups of the nucleophiles used. This seems especially plausible when considering how for SMA-Glu, the peak at $1779 \mathrm{~cm}^{-1}$ is more intense than the $1778 \mathrm{~cm}^{-1}$ peak in SMA-AE. This would be a result of the presence of five hydroxyl groups in glucosamine as opposed to just one in aminoethanol, resulting in more ester bonds formed when glucosamine is used.

As expected, SMA-Neut and SMA-Pos both display low wavenumber peaks for their carboxylic acids, which are deprotonated as a result of their preparation and/or the presence of basic amine groups in the polymers. They also display weak peaks in the typical carboxylic acid range, which we attribute to the protonated forms of carboxylic acids in the polymers, which may be present in a lower proportion.

\section{Solution NMR Spectroscopy of sMa Derivatives.}

Generally, NMR spectra of polymers can be difficult to assign and interpret, especially for polymers almost $10 \mathrm{kDa}$ in size and with complex internal structure such as the alternation and block-like structure in SMA. Assignment is difficult because the size and complex structure of these derivatives cause peaks to appear as multiplets and also broaden out, frustrating meaningful peak integration. Generally, this broadening is most substantially closer to the backbone, which helped inform some of the peak assignments; sharper peaks were assumed to be further from the backbone where fast isotropic motion could more easily occur. Nevertheless, Tables S5-S8 give proposed assignments of NMR spectra of the SMAAE, SMA-Glu, SMA-Neut, and SMA-Pos derivatives. NMR spectra are given in Figure 4. 


\section{Formation and Stability of Lipid Disks.}

The performance of SMA polymers and their derivatives in forming nanoscale disk-like particles is a critical parameter to evaluate the impact of these derivatives. Vesicles of 25 $\mathrm{mM}$ POPC were titrated with ca. 2.5\% (w/v) solutions of polymer up to a volume ratio of 1:1.5 (Figure 5a-e), which is a typical lipid/polymer ratio used in SMALP-like systems. These SMADLPs typically resulted in narrow particle diameter distributions shifted by a factor of 4-8, as measured by DLS. All polymers formed nanoparticles (SMADLPs) of sizes in good agreement with our previous work, ${ }^{18,29,31}$ where 2-1M SMA formed SMADLPs with an average particle diameter of $28 \mathrm{~nm}$ and 3-1M SMA formed SMADLPs with a particle diameter of $10 \mathrm{~nm} .{ }^{18}$ The SMADLPs in this work are also likely to be formed as disk-like aggregates of lipid molecules, wrapped by the synthetic polymer, where the styrene units interact with lipid hydrophobic chains, and the polar maleic acid derivative is exposed to the aqueous phase.

All five of the copolymers used were capable of forming SMADLPs, although their level of performance varies. 2-1M SMA-Glu, 2-1M SMA-Pos, and 3-1M SMA-Pos (5a,d,e) display high-diameter shoulders that appear to be unreacted POPC vesicles, and this is most pronounced for the SMA-Pos samples. This indicates that these materials may not be effective at solubilizing vesicles. SMA-Glu, SMA-Neut, and 3-1M SMA-Pos (5a,b,e) also display some very large particles near or above $1000 \mathrm{~nm}$ in diameter. These may be aggregates of many nanodisks, which can be seen in some of the transmission electron microscopy (TEM) images (Figure S1c). The samples were allowed to sediment for $24 \mathrm{~h}$ before data collection, so these particles must not have significantly higher density than the bulk solution, leading us to conclude that they are composed largely of lipids.

Finally, the SMADs used generate SMADLPs in two distinct size ranges. The polymers in the smaller size category (SMA-Glu, SMA-AE, 2-1M SMA-Pos) have characteristics associated with hard surfactants, whereas those in the larger size category (SMA-Neut and 3-1M SMA-Pos) have characteristics associated with soft surfactants. As discussed in the Introduction, the softness of a surfactant refers to its tendency to not disrupt native protein structure, with the caveat that a soft surfactant is not effective at solubilizing membranes. Having a zwitterionic or uncharged polar head group makes a surfactant softer than a head group with net charge. Despite the difference in scale, the same relationship seems to apply for SMADLPs because the zwitterionic SMA-Neut produced particles of larger size than the polymers with overall net charge. Having a longer acyl chain also makes for a softer surfactant. As seen in Figure 5e, 3-1M SMA-Pos produced significantly larger particles than 2-1M SMA-Pos (5d). The only chemical difference between these two polymers is that $3-$ 1M SMA has a longer styrene tail; the alternating region should be of almost exactly the same structure between these two copolymers. The styrene tail may be acting to soften the surfactant character of 3-1M SMA-Pos, which hampered its ability to form nanoparticles.

The copolymer-lipid nanoparticles generated from the SMADs in this study are very robust against both $\mathrm{pH}$ and magnesium. SMALPs are known to be sensitive to $\mathrm{pH}$ values below 6 and sensitive to even modest concentrations of magnesium at or below $10 \mathrm{mM} .{ }^{32}$ Figure $6 \mathrm{a}$ shows the overall robust $\mathrm{pH}$ behavior of the SMADLPs. SMA-Pos is highly sensitive to $\mathrm{pH}$ 5 but tolerates $\mathrm{pH} 3$ and 9 . This behavior is predicted by the $\mathrm{p} K_{\mathrm{a}}$ experiment, where the 
cloudy SMA-Pos solution clarified as the $\mathrm{pH}$ was raised past 5.63. SMA-Glu nanoparticles begin to become cloudy at $\mathrm{pH} 3$ but only slightly and tolerate the other $\mathrm{pH}$ values as well. SMA-AE and SMA-Neut are completely insensitive to all $\mathrm{pH}$ values tested. These results are in contrast to previously reported maleimide derivatives, which can be sensitive to high $\mathrm{pH}$.

Figure $6 \mathrm{~b}$ shows that the SMADLPs are completely insensitive to $\mathrm{Mg}^{2+}$. In our experiment, the synthesized SMA seems to be less sensitive to Mg than usual, but this is accounted for by the high polymer/lipid ratio used in this experiment (7.5:1), which was used to limit the size of the pellets seen in the SMADLP samples. In any case, a sharp increase in turbidity is observed for SMA from 20 to $40 \mathrm{mM}$, while the SMADLPs had no observable response to even $100 \mathrm{mM}$ magnesium (Figure 6b), which is due to the loss of the strong chelating character of the diacids present in SMA.

\section{Incorporation of KCNE1-58 into Nanodisks.}

$\mathrm{KCNE} 1$ is a 129 amino acid, single transmembrane protein that assists in the proper functioning of several voltage-gated potassium ion channels. ${ }^{25,28,33}$ Mutations of genes that code for KCNE1 protein cause congenital deafness, congenital long QT syndrome, ventricular tachyarrhythmia, syncope, and sudden cardiac death. ${ }^{28,34,35}$

This study serves as a guide to help determine which SMADLP system to use based on the overall charge of the membrane protein of interest to reconstitute. In this study, human KCNE1 with a spin label in the transmembrane domain (introduced via a mutant cysteine residue, T58C) was incorporated into two different nanodisks; each SMADLP system contained polymer belts SMA-Glu and SMA-AE. CW-EPR lineshape analysis was used to compare T58C reconstituted in the two nanodisk systems to T58C reconstituted into POPC/ POPG vesicles. The lineshape of the control is verified by comparing it to the literature that has already characterized this transmembrane protein in both lipid bilayers and SMALPs. ${ }^{36}$ Despite the ability for any SMA derivative to spontaneously form nanodisks when mixed with vesicles, a recent study has transformed our understanding of protein functionality when reconstituted into nanodisks; using a variety of biophysical techniques, this study confirmed protein dynamics and functionality are preserved when overall protein charge matches that of the polymer belt. ${ }^{37}$ Human KCNE1, a negatively charged protein at $\mathrm{pH}$, was reconstituted into nanodisks with SMA-Glu and SMA-AE, both negatively charged polymers, to preserve a more native environment.

The lineshape of the reconstituted mutant KCNE1 into SMA-AE (Figure 7c) nanodisks shows significant amplification of the slow/rigid component of the spin label much similar to that of previous studies that use traditional SMA to reconstitute transmembrane proteins into nanodisks. ${ }^{29,36}$ Interestingly, reconstitution of the mutant KCNE1 into SMA-Glu nanodisks (Figure 7d) only slightly magnifies the slow/rigid component of the spin label and closely resembles the lineshape of the control (Figure 7b).

These differences in lineshapes are due to the relationship of the charge density of the polymer belt to the charge density of the membrane protein. Using SMA-AE (7c), the CWEPR lineshape is most similar to lineshapes of similar mutants reconstituted into nanodisks 
with traditional SMA because of similarity in high charge density between the two polymers. SMA-Glu has a lower charge density than SMA-AE or SMA and displays a lineshape most similar to the control.

Human KCNE1 mutant T58C has a relatively low charge density because of the similar number of negatively charged residues (13) and positively charged residues (16, including 3 histidines), resulting in a calculated charge between -1 and 0 at $\mathrm{pH} 7$. Not only has this study shown to preserve protein dynamics of KCNE1 using negatively charged polymer belts, but CW-EPR lineshape analysis reveals differences in protein dynamics based on the charge density of the polymer belt. Analysis of the lineshapes shows that SMA-Glu provides the more suitable membrane mimetic system for KCNE1.

\section{CONCLUSIONS}

Multiple derivatives of SMA were synthesized by taking advantage of the high reactivity of the maleic anhydride functionality of the parent polymer. The GPC data support preservation of the low dispersity of SMA-AE, SMA-Pos, and SMA-Neut. The infrared spectra show efficient conversion of the anhydride groups to give a functional polymer, suggesting complete functionalization for each derivative. It is noteworthy that essentially complete conversion of the anhydride occurs in each system, despite the rapid and mild conditions used in the functionalization step. Several SMA derivative polymers display $\mathrm{p} K_{\mathrm{a}}$ values far outside the range expected of carboxylic acids, especially SMA-Glu, which shows a weak buffering region near neutral $\mathrm{pH}$. We attribute this behavior to the unique macromolecular structure of the copolymers. The NMR data are unique for each polymer, and despite the complexity, each proton in the intended products can be assigned, indicating successful reaction. All of the copolymers were capable of reacting with POPC vesicles to form SMADLPs of varying sizes, and there is some correlation between the net polymer charge and the sizes of particles formed. All the SMADLPs display robust physical characteristics, functioning at a wide $\mathrm{pH}$ range and up to $100 \mathrm{mM}$ magnesium. Finally, we observed reconstitution of the transmembrane protein KCNE1 into SMADLPs by CW-EPR, finding that minimal perturbation of protein dynamics occurred when using SMA-Glu, which has the lowest charge density of the negatively charged polymers. This work highlights the potential of the styrene-maleic anhydride polymers toward the facile development of functional surfactants and will encourage the syntheses of materials with a wider range of uses than the current SMA standard.

\section{Supplementary Material}

Refer to Web version on PubMed Central for supplementary material.

\section{ACKNOWLEDGMENTS}

This work was generously supported by NIGMS/NIH Maximizing Investigators' Research Awards (MIRA) R35GM126935 (GAL) and R35GM128595 (RCP) and NSF grant CHE-1807131 (GAL), the Ohio Board of Regents, and Miami University. G.A.L. would also like to acknowledge support from the John W. Steube Professorship. D.K would also like to acknowledge support from the Robert H. and Nancy J. Blayney Professorship. D.K. and R.C.P. would also like to acknowledge support from The Army Research Office (Award\# 74112-CH-II). 


\section{REFERENCES}

(1). Bull SC; Doig AJ Properties of Protein Drug Target Classes. PLoS One 2015, 10, No. e0117955.

(2). Yin H; Flynn AD Drugging Membrane Protein Interactions. Annu. Rev. Biomed. Eng 2016, 18, 51-76. [PubMed: 26863923]

(3). Overington JP; Al-Lazikani B; Hopkins AL How Many Drug Targets Are There? Nat. Rev. Drug Discovery 2006, 5, 993-996. [PubMed: 17139284]

(4). Sachs JN; Engelman DM Introduction to the Membrane Protein Reviews: The Interplay of Structure, Dynamics, and Environment in Membrane Protein Function. Annu. Rev. Biochem 2006, 75, 707-712. [PubMed: 16756508]

(5). Tate CG Practical Considerations of Membrane Protein Instability during Purification and Crystallisation. Methods Mol. Biol 2010, 601, 187-203. [PubMed: 20099147]

(6). Hardy D; Desuzinges Mandon E; Rothnie AJ; Jawhari A The Yin and Yang of Solubilization and Stabilization for Wild-Type and Full-Length Membrane Protein. Methods 2018, 147, 118-125. [PubMed: 29477816]

(7). Ujwal R; Bowie JU Crystallizing Membrane Proteins Using Lipidic Bicelles. Methods 2011, 55, 337-341. [PubMed: 21982781]

(8). Dürr UHN; Soong R; Ramamoorthy A When Detergent Meets Bilayer: Birth and Coming of Age of Lipid Bicelles. Prog. Nucl. Magn. Reson. Spectrosc 2013, 69, 1-22. [PubMed: 23465641]

(9). Raschle T; Hiller S; Etzkorn M; Wagner G Nonmicellar Systems for Solution NMR Spectroscopy of Membrane Proteins. Curr. Opin. Struct. Biol 2010, 20, 471-479. [PubMed: 20570504]

(10). Shen H-H; Lithgow T; Martin L Reconstitution of Membrane Proteins into Model Membranes: Seeking Better Ways to Retain Protein Activities. Int. J. Mol. Sci 2013, 14, 1589-1607. [PubMed: 23344058]

(11). Bayburt TH; Grinkova YV; Sligar SG Self-Assembly of Discoidal Phospholipid Bilayer Nanoparticles with Membrane Scaffold Proteins. Nano Lett. 2002, 2, 853-856.

(12). Larsen AN; Sørensen KK; Johansen NT; Martel A; Kirkensgaard JJK; Jensen KJ; Arleth L; Midtgaard SR Dimeric Peptides with Three Different Linkers Self-Assemble with Phospholipids to Form Peptide Nanodiscs That Stabilize Membrane Proteins. Soft Matter 2016, 12, 5937-5949. [PubMed: 27306692]

(13). Kondo H; Ikeda K; Nakano M Formation of Size-Controlled, Denaturation-Resistant Lipid Nanodiscs by an Amphi-philic Self-Polymerizing Peptide. Colloids Surf., B 2016, 146, 423-430.

(14). Bayburt TH; Sligar SG Membrane Protein Assembly into Nanodiscs. FEBS Lett. 2010, 584, 1721-1727. [PubMed: 19836392]

(15). Burridge KM; Wright TA; Page RC; Konkolewicz D Photochemistry for Well-Defined Polymers in Aqueous Media: From Fundamentals to Polymer Nanoparticles to Bioconjugates. Macromol Rapid Commun. 2018, 39, 1800093-1800114.

(16). Xue M; Cheng L; Faustino I; Guo W; Marrink SJ Molecular Mechanism of Lipid Nanodisk Formation by Styrene-Maleic Acid Copolymers. Biophys. J 2018, 115, 494-502. [PubMed: 29980293]

(17). Zhang R; Sahu ID; Bali AP; Dabney-Smith C; Lorigan GA Characterization of the Structure of Lipodisq Nanoparticles in the Presence of KCNE1 by Dynamic Light Scattering and Transmission Electron Microscopy. Chem. Phys. Lipids 2017, 203, 19-23. [PubMed: 27956132]

(18). Craig AF; Clark EE; Sahu ID; Zhang R; Frantz ND; Al-Abdul-Wahid MS; Dabney-Smith C; Konkolewicz D; Lorigan GA Tuning the Size of Styrene-maleic Acid Copolymer-Lipid Nanoparticles (SMALPs) Using RAFT Polymerization for Biophysical Studies. Biochim. Biophys. Acta, Biomembr 2016, 1858, 2931-2939.

(19). Dörr JM; Scheidelaar S; Koorengevel MC; Dominguez JJ; Schäfer M; van Walree CA; Killian JA The Styrene-maleic acid copolymer: a versatile tool in membrane research. Eur. Biophys. J 2016, 45, 3-21. [PubMed: 26639665]

(20). Fiori MC; Jiang Y; Altenberg GA; Liang H Polymer-Encased Nanodiscs with Improved Buffer Compatibility. Sci. Rep 2017, 7, 7432. [PubMed: 28785023] 
(21). Ravula T; Hardin NZ; Ramadugu SK; Cox SJ; Ramamoorthy A Formation of PH-Resistant Monodispersed Polymer-Lipid Nanodiscs. Angew. Chem., Int. Ed 2018, 57, 1342-1345.

(22). Ravula T; Hardin NZ; Ramadugu SK; Ramamoorthy A PH Tunable and Divalent Metal Ion Tolerant Polymer Lipid Nanodiscs. Langmuir 2017, 33, 10655-10662. [PubMed: 28920693]

(23). Ravula T; Ramadugu SK; Di Mauro G; Ramamoorthy A Bioinspired, Size-Tunable SelfAssembly of Polymer-Lipid Bilayer Nanodiscs. Angew. Chem 2017, 129, 11624-11628.

(24). Newstead S; Ferrandon S; Iwata S Rationalizing a-helical membrane protein crystallization. Protein Sci. 2008, 17, 466-472. [PubMed: 18218713]

(25). Coey AT; Sahu ID; Gunasekera TS; Troxel KR; Hawn JM; Swartz MS; Wickenheiser MR; Reid R.-j; Welch RC; Vanoye CG; Kang C; Sanders CR; Lorigan GA Reconstitution of KCNE1 into Lipid Bilayers: Comparing the Structural, Dynamic, and Activity Differences in Micelle and Vesicle Environments. Biochemistry 2011, 50, 10851-10859. [PubMed: 22085289]

(26). Gennis RB Biomembranes : Molecular Structure and Function; Springer: New York, 1989.

(27). Hall SCL; Tognoloni C; Charlton J; Bragginton ÉC; Rothnie AJ; Sridhar P; Wheatley M; Knowles TJ; Arnold T; Edler KJ; Dafforn TR An Acid-Compatible Co-Polymer for the Solubilization of Membranes and Proteins into Lipid Bilayer-Containing Nanoparticles. Nanoscale 2018, 10, 10609-10619. [PubMed: 29845165]

(28). Tian C; Vanoye CG; Kang C; Welch RC; Kim HJ; George AL; Sanders CR Preparation, Functional Characterization, and NMR Studies of Human KCNE1, a Voltage-Gated Potassium Channel Accessory Subunit Associated with Deafness and Long QT Syndrome. Biochemistry 2007, 46, 11459-11472. [PubMed: 17892302]

(29). Harding BD; Dixit G; Burridge KM; Sahu ID; Dabney-Smith C; Edelmann RE; Konkolewicz D; Lorigan GA Characterizing the Structure of Styrene-maleic Acid Copolymer-Lipid Nanoparticles (SMALPs) Using RAFT Polymerization for Membrane Protein Spectroscopic Studies. Chem. Phys. Lipids 2019, 218, 65-72. [PubMed: 30528635]

(30). Koper GJM; Borkovec M Proton Binding by Linear, Branched, and Hyperbranched Polyelectrolytes. Polymer 2010, 51, 5649-5662.

(31). Bali AP; Sahu ID; Craig AF; Clark EE; Burridge KM; Dolan MT; Dabney-Smith C; Konkolewicz D; Lorigan GA Structural Characterization of Styrene-maleic Acid CopolymerLipid Nanoparticles (SMALPs) Using EPR Spectroscopy. Chem. Phys. Lipids 2019, 220, 6-13. [PubMed: 30796886]

(32). Dörr JM; Scheidelaar S; Koorengevel MC; Dominguez JJ; Schäfer M; van Walree CA; Killian JA The Styrene-maleic acid copolymer: a versatile tool in membrane research. Eur. Biophys. J 2016, 45, 3-21. [PubMed: 26639665]

(33). Kang Q; Zhao Z-A; You S-L Highly Enantioselective Friedel-Crafts Reaction of Indoles with Imines by a Chiral Phosphoric Acid. J. Am. Chem. Soc 2007, 129, 1484-1485. [PubMed: 17283980]

(34). Wang Z; Fermini B; Nattel S Rapid and Slow Components of Delayed Rectifier Current in Human Atrial Myocytes. Cardiovasc. Res 1994, 28, 1540-1546. [PubMed: 8001043]

(35). Harmer SC; Tinker A The Role of Abnormal Trafficking of KCNE1 in Long QT Syndrome 5. Biochem. Soc. Trans 2007, 35, 1074-1076. [PubMed: 17956282]

(36). Sahu ID; Zhang R; Dunagan MM; Craig AF; Lorigan GA Characterization of KCNE1 inside Lipodisq Nanoparticles for EPR Spectroscopic Studies of Membrane Proteins. J. Phys. Chem. B 2017, 121, 5312-5321. [PubMed: 28485937]

(37). Ravula T; Hardin NZ; Bai J; Im S-C; Waskell L; Ramamoorthy A Effect of Polymer Charge on Functional Reconstitution of Membrane Proteins in Polymer Nanodiscs. Chem. Commun 2018, 54, 9615-9618. 


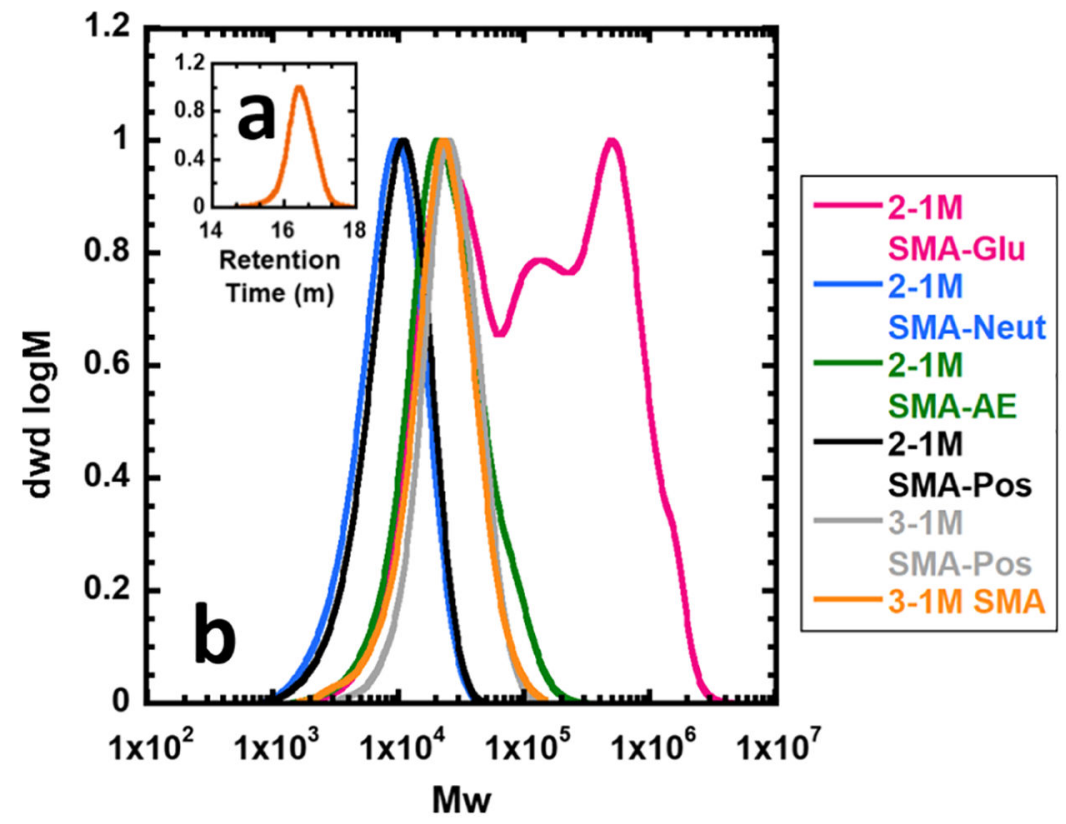

Figure 1.

GPC traces of SMA materials. (a) (inset) 2-1M styrene-maleic anhydride starting material in THF. (b) SMA derivatives in DMF. Maximum intensity normalized to 1. 

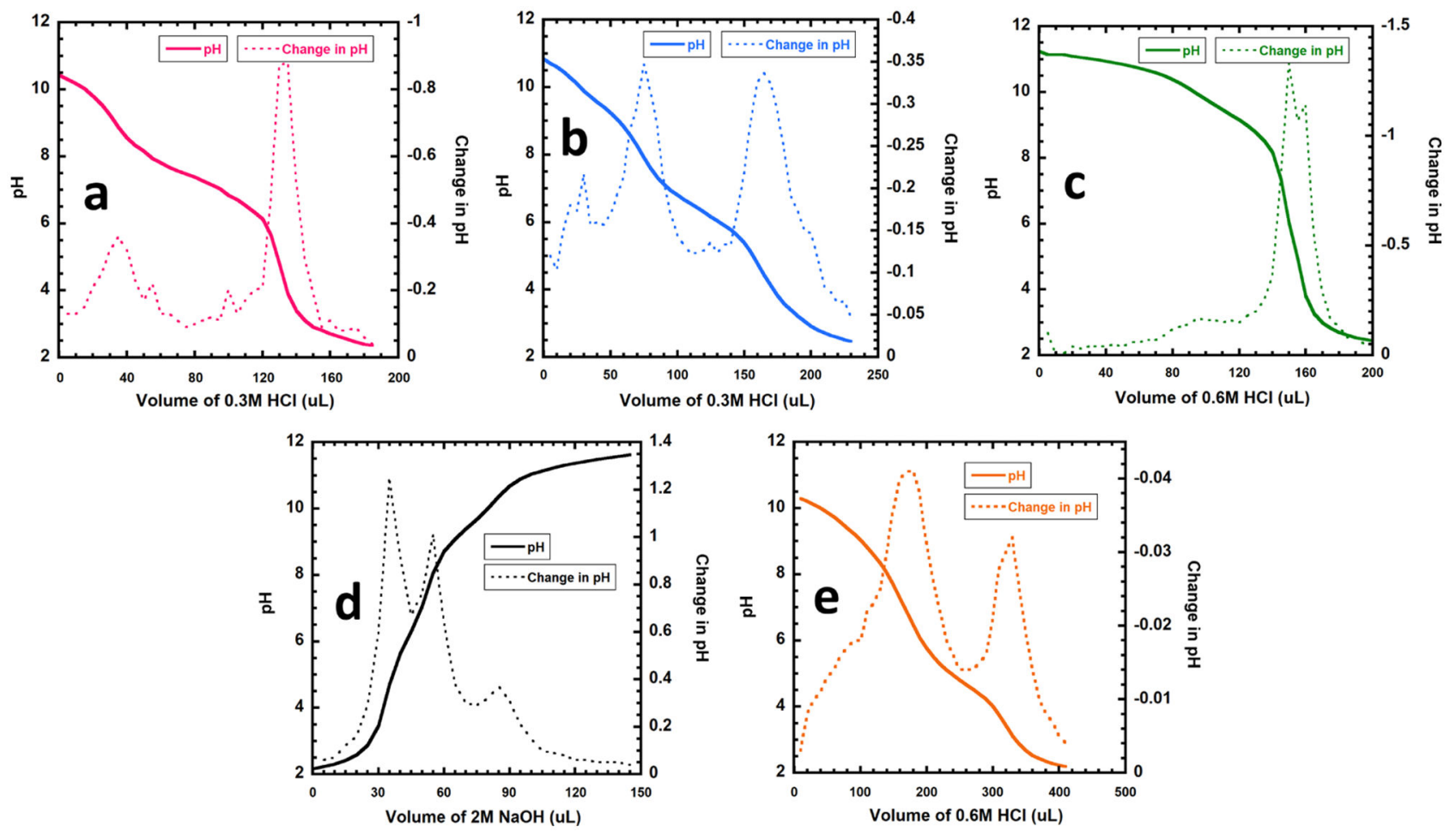

Figure 2.

Titration curves of SMA derivatives. (a) 2-1M SMA-Glu; (b) 2-1M SMA-Neut; (c) 2-1M SMA-AE; (d) 2-1M SMA-Pos; and (e) 2-1M SMA for reference. 

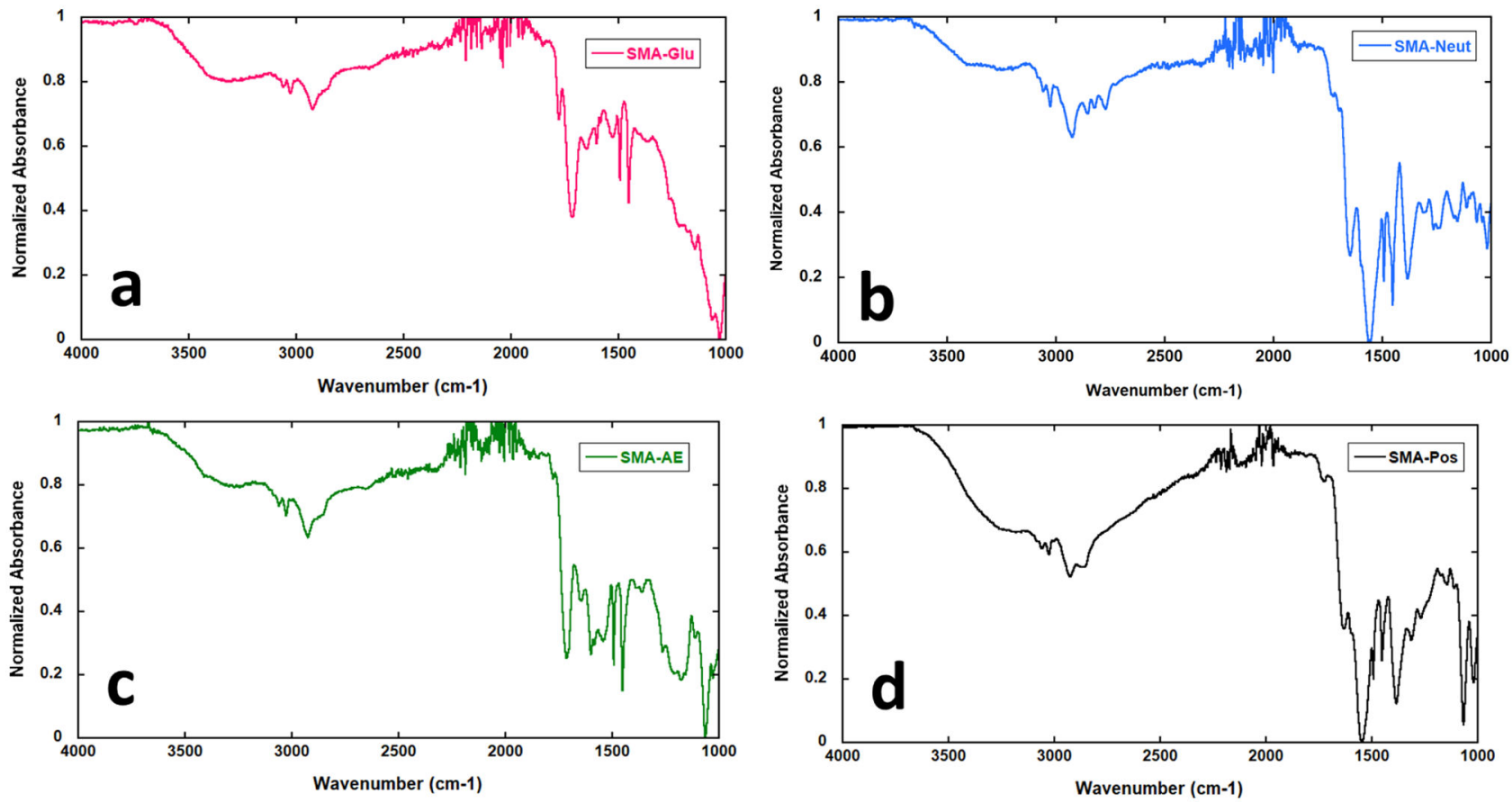

Figure 3.

Infrared spectra of SMA derivatives. (a) 2-1M SMA-Glu; (b) 2-1M SMA-Neut; (c) 2-1M SMA-AE; and (d) 2-1M SMA-Pos. 

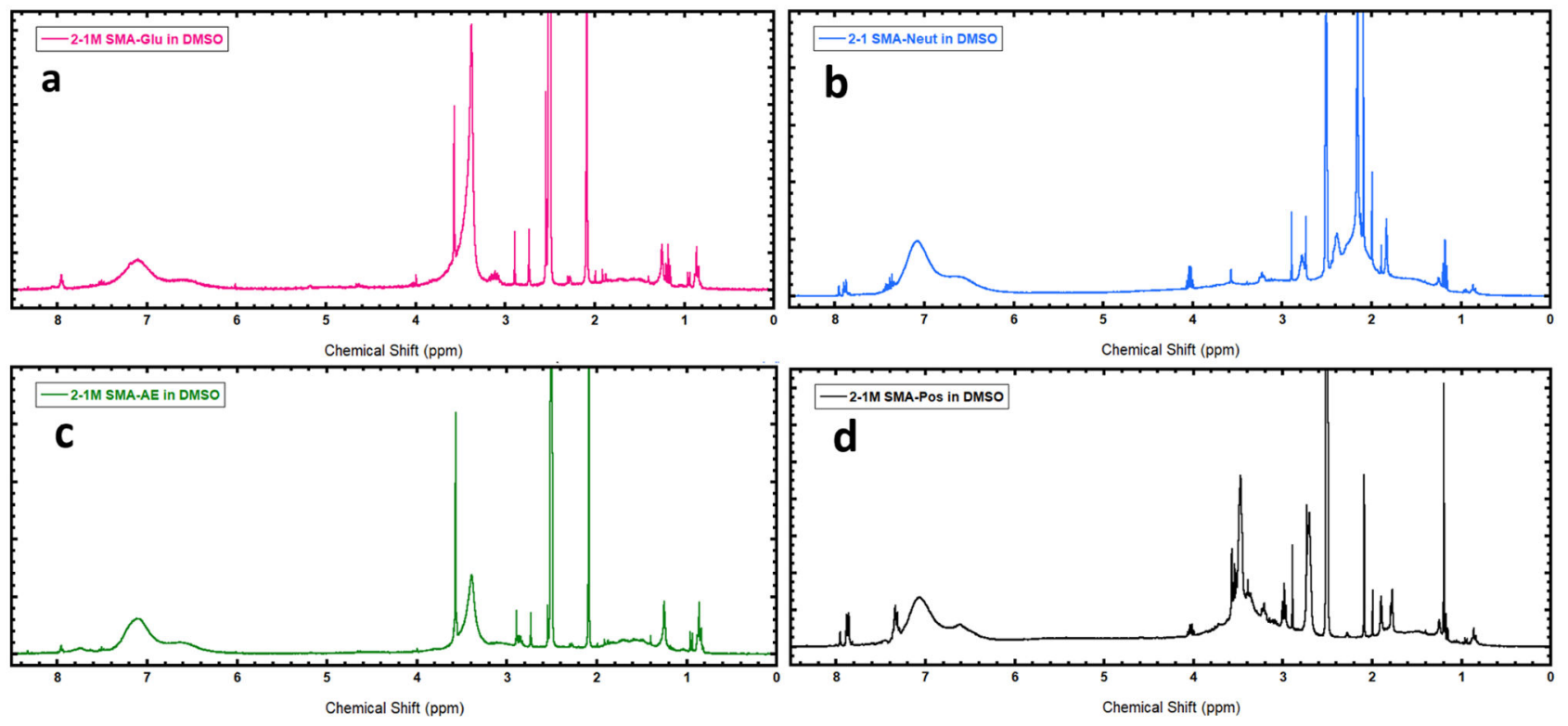

Figure 4.

Solution NMR spectra of SMA derivatives. (a) 2-1M SMA-Glu; (b) 2-1M SMA-Neut; (c) 2-1M SMA-AE; and (d) 2-1M SMA-Pos. 

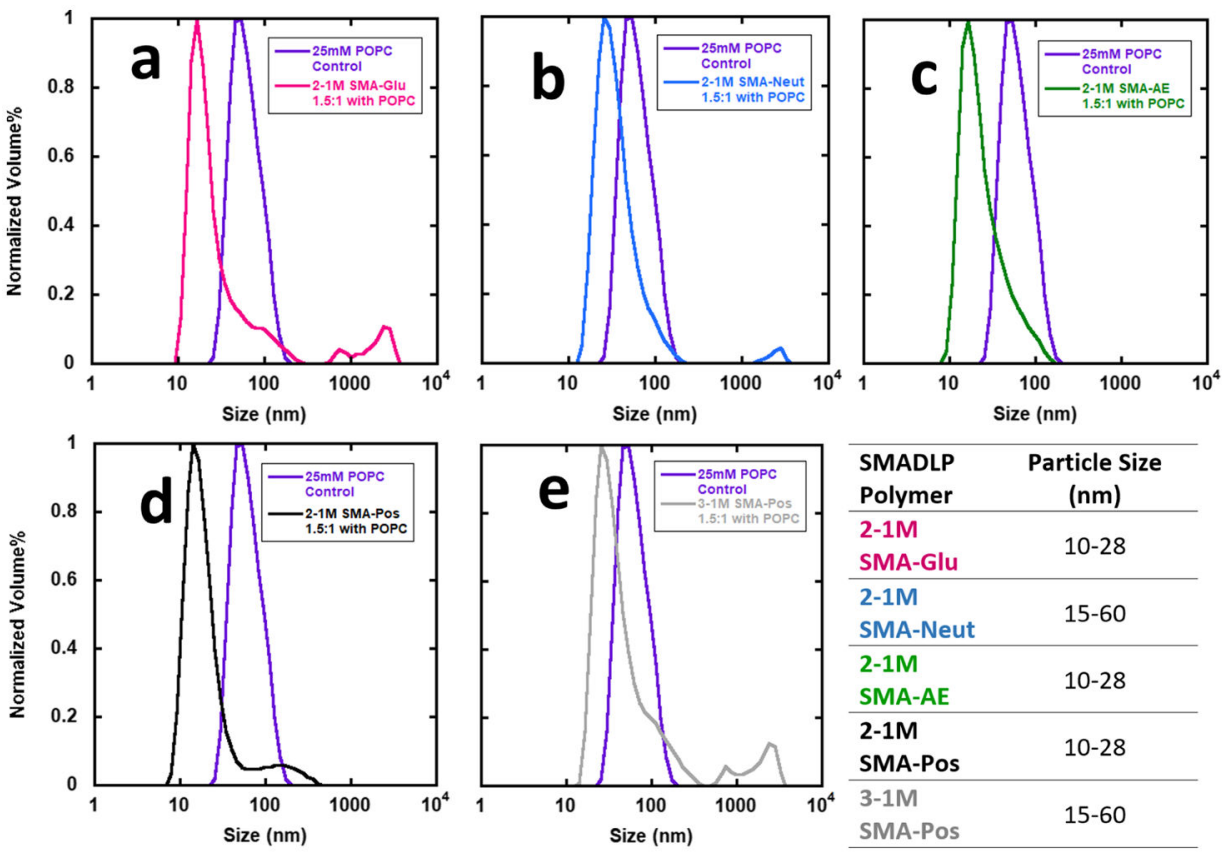

Figure 5.

DLS volume plots of nanoparticles formed by SMA derivatives titrated in a 1.5:1 polymer/ lipid ratio (v/v). (a) 2-1M SMA-Glu; (b) 2-1M SMA-Neut; (c) 2-1M SMA-AE; (d) 2-1M SMA-Pos; and (e) 3-1M SMA-Pos. 

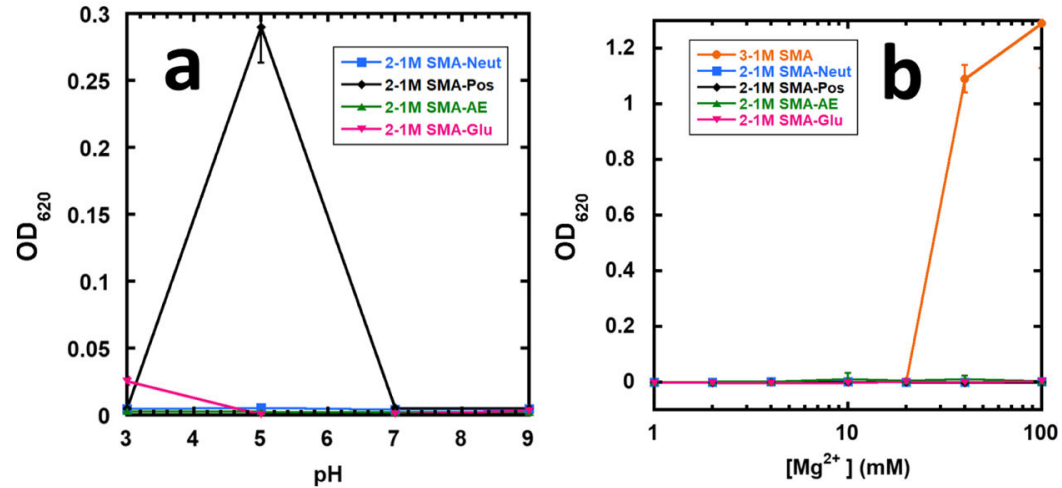

Figure 6.

Stability of SMADLPs against (a) pH and (b) magnesium ions. SMADLPs and SMALPS were formed by combining SMAD or SMA and POPC at approximately a 7.5:1 weight ratio. 


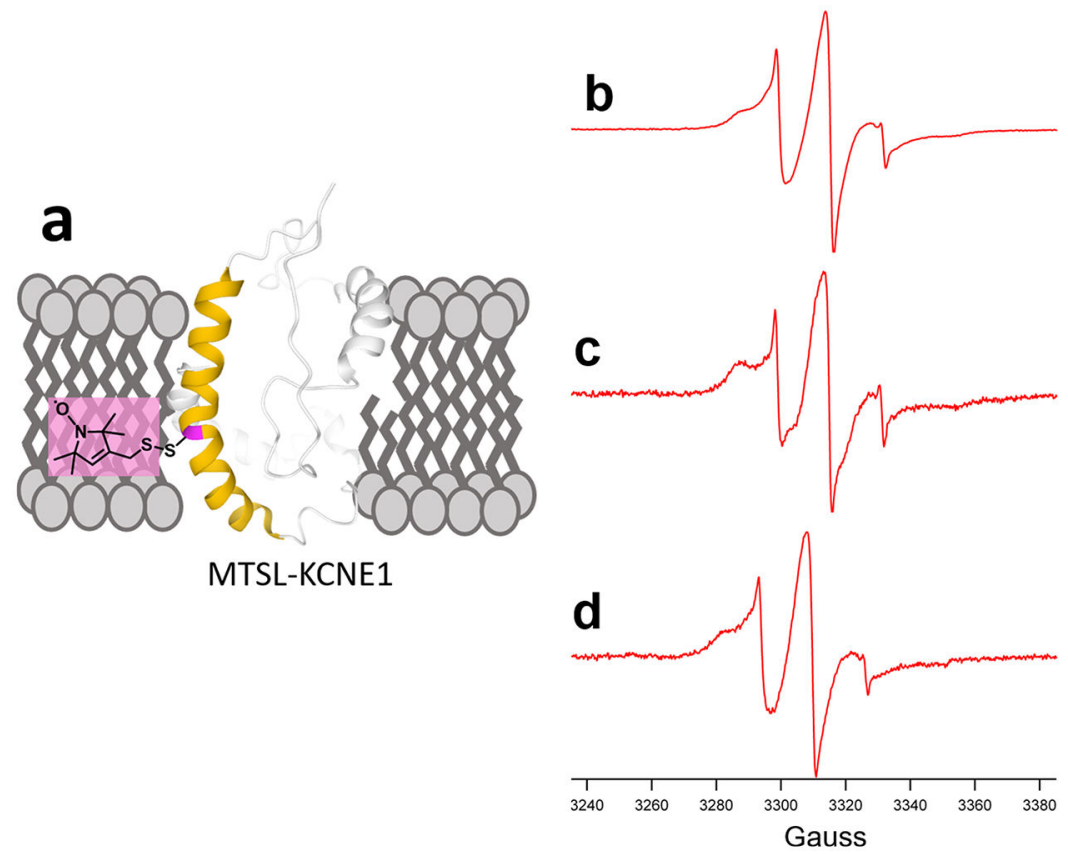

Figure 7.

CW-EPR spectra of (a) MTSL spin-labeled KCNE1 T58C reconstituted in (b) POPC/POPG liposomes, (c) SMA-AE nanodisks, and (d) SMA-Glu nanodisks.

Biomacromolecules. Author manuscript; available in PMC 2020 April 21. 

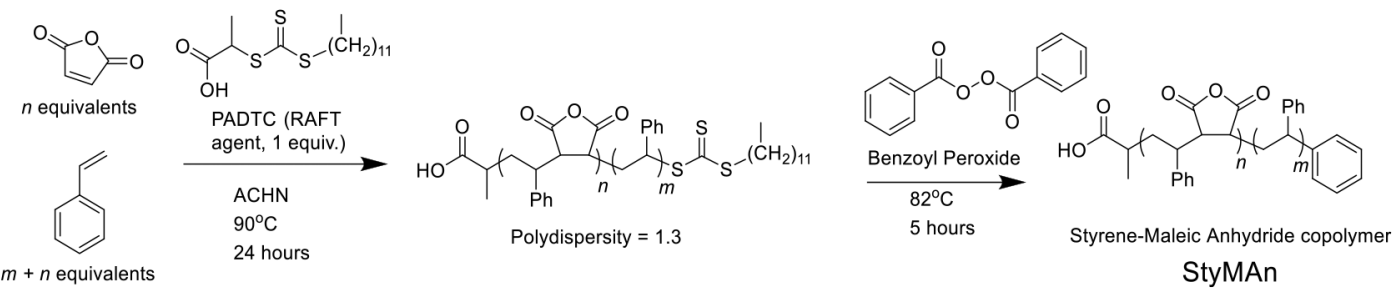

Scheme 1. Synthesis of a Styrene-Maleic Acid Copolymer with Styrene Tail 
Table 1.

SMA Derivatives for New SMALP Formulations

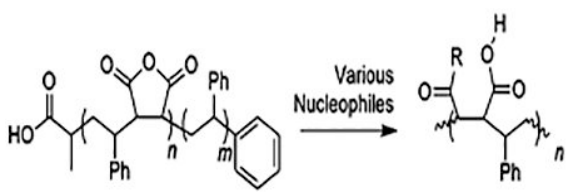

Product Name R-group


Table 2.

\begin{tabular}{|c|c|c|c|}
\hline \multirow{7}{*}{ 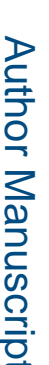 } & \\
\hline & polymer & Mn (kDa) & PD \\
\hline & 2-1M SMA-Glu & 42.1 & 6.93 \\
\hline & 2-1M SMA-Neut & 6.9 & 1.46 \\
\hline & 2-1M SMA-AE & 18.3 & 1.72 \\
\hline & 2-1M SMA-Pos & 11.1 & 1.43 \\
\hline & 3-1M SMA-Pos & 21.9 & 1.33 \\
\hline & 3-1M SMA & 17.8 & 1.51 \\
\hline & 2-1M SMAn & 6.8 & 1.29 \\
\hline
\end{tabular}


$\mathrm{p} K_{\mathrm{a}}$ Analysis of Derivatives

\begin{tabular}{|c|c|c|c|}
\hline polymer & $\mathrm{p} K_{\mathrm{a} 1}$ & $\mathrm{p} K_{\mathrm{a} 2}$ & macroscopic behavior \\
\hline SMA-Glu & 7.4 & & no precipitated observed \\
\hline SMA-Neut & 6.4 & 10.4 & no precipitated observed \\
\hline SMA-AE & 9.5 & & $\begin{array}{l}\text { above } \mathrm{pH} 2.3 \text {, the undissolved material swells and forms a gel-like phase. Below } \mathrm{pH} 2.3 \text {, the transparent solution } \\
\text { becomes cloudy, and the nebulous material settles to bottom within } 24 \mathrm{~h} \text {. }\end{array}$ \\
\hline SMA-Pos & 6.3 & 9.7 & cloudy solution quickly clarifies when moving from pH 5.63 to $\mathrm{pH} 6.30$. \\
\hline
\end{tabular}

polymer

no precipitated observed

\section{Table 3.}

